\title{
Insecticidal activities of leaf essential oils from Cinnamomum osmophloeum against three mosquito species
}

\author{
Sen-Sung Cheng ${ }^{\mathrm{a}}$, Ju-Yun Liu ${ }^{\mathrm{b}}$, Chin-Gi Huang ${ }^{\mathrm{c}}$, Yen-Ray Hsui ${ }^{\mathrm{d}}$, \\ Wei-June Chen ${ }^{\mathrm{e}}$, Shang-Tzen Chang ${ }^{\mathrm{b}, *}$ \\ ${ }^{a}$ Experimental Forest, National Taiwan University, Nan-Tou 557, Taiwan \\ ${ }^{\mathrm{b}}$ School of Forestry and Resource Conservation, National Taiwan University, No. 1, Sec. 4, Roosevelt Road, Taipei 106, Taiwan \\ ${ }^{\mathrm{c}}$ Department of Entomology, National Taiwan University, Taipei 106, Taiwan \\ ${ }^{\mathrm{d}}$ Chung-Pu Research Center, Taiwan Forestry Research Institute, Chiayi 600, Taiwan \\ ${ }^{\mathrm{e}}$ Department of Public Health and Parasitology, Chang Gung University, Kwei-San, Tao-Yuan 33332, Taiwan
}

Received 10 October 2007; received in revised form 19 February 2008; accepted 20 February 2008

Available online 18 April 2008

\begin{abstract}
The larvicidal activities of leaf essential oils and their constituents from six chemotypes of indigenous cinnamon (Cinnamomum osmophloeum Kaneh.) trees were evaluated against three mosquito species. Results of larvicidal tests demonstrated that the leaf essential oils of cinnamaldehyde type and cinnamaldehyde/cinnamyl acetate type had an excellent inhibitory effect against Aedes albopictus larvae, and their $\mathrm{LC}_{50}$ values in $24 \mathrm{~h}$ were $40.8 \mu \mathrm{g} / \mathrm{ml}\left(\mathrm{LC}_{90}=81.7 \mu \mathrm{g} / \mathrm{ml}\right)$ and $46.5 \mu \mathrm{g} / \mathrm{ml}\left(\mathrm{LC}_{90}=83.3 \mu \mathrm{g} / \mathrm{ml}\right)$, respectively. Results of the $24-\mathrm{h}$ mosquito larvicidal assays also showed that the effective constituents in leaf essential oils were trans-cinnamaldehyde and benzaldehyde and that the $\mathrm{LC}_{50}$ values of these constituents against $A$. albopictus larvae were below $50 \mu \mathrm{g} / \mathrm{ml}$. In addition, cinnamaldehyde type leaf essential oil and trans-cinnamaldehyde have also exhibited great larvicidal performance against Culex quinquefasciatus and Armigeres subalbatus larvae. Comparisons of mosquito larvicidal activity of trans-cinnamaldehyde congeners revealed that $\alpha$-methyl cinnamaldehyde, benzaldehyde, and trans-cinnamaldehyde exhibited strong mosquito larvicidal activity.
\end{abstract}

(c) 2008 Elsevier Ltd. All rights reserved.

Keywords: Cinnamomum osmophloeum; Essential oils; Aedes albopictus; Culex quinquefasciatus; Armigeres subalbatus

\section{Introduction}

The search for new strategies or natural products to control destructive insects and vectors of diseases is desirable due to the prevalent occurrence of vector resistance to synthetic insecticides and the problem of toxic non-biodegradable residues contaminating the environment and undesirable effects on nontarget organisms (Jantan et al., 2005). It has been shown that the use of plant essential oils as mosquito control agents can be effective, and it has been shown to minimize the impact that most pesticidal com-

\footnotetext{
* Corresponding author. Tel.: +88623366 4626; fax: +886223654520. E-mail address: peter@ntu.edu.tw (S.-T. Chang).
}

pounds impose on the environment (Fatope et al., 1993). Mosquitoes play a predominant role in the transmission of some important diseases such as dengue fever, Japanese encephalitis, malaria, and viral diseases which are today among the greatest health problems in the world (Cheng et al., 2004; Hemingway, 2004; Kuo et al., 2007). In recent years, dengue fever cases have increased significantly in Taiwan (Lee et al., 2006), and much effort has been focused on exploring bioactive chemical compounds from indigenous plants for mosquito control (Chang et al., 2003; Cheng et al., 2003, 2004, 2008; Kuo et al., 2007).

Lauraceae is an economically important family consisting mostly of trees. The genus Cinnamomum comprises about 250 species distributed in Asia and Australia (Jayaprakasha et al., 2003). Indigenous cinnamon (Cinnamomum 
osmophloeum Kaneh.) (Cinnamomum) is an endemic tree that grows in Taiwan's natural hardwood forests at elevations between 400 and $1500 \mathrm{~m}$. It has been of interest to researchers because the chemical constituents of its leaf essential oil are similar to those of Cinnamomum cassia bark oil (Chang et al., 2001; Hu et al., 1985). Our previous studies have demonstrated that leaf essential oils from $C$. osmophloeum had excellent antibacterial, antitermite, antimite, antimildew, antipathogenic, antifungal, and antiinflammatory activities (Chang et al., 2001; Chang and Cheng, 2002; Chen et al., 2002; Chen and Chang, 2002; Cheng et al., 2006; Lee et al., 2005; Wang et al., 2005; Chao et al., 2005, 2008). In addition, we found that essential oil and cinnamaldehyde from the leaves of C. osmophloeum exhibited the strongest mosquito larvicidal activity against fourth-instar Aedes aegypti larvae (Cheng et al., 2004). It is interesting to know whether the essential oil and its constituents from the leaves of C. osmophloeum possess the inhibitory action against other mosquito species. Thus, in this study we present the chemical composition of the leaf essential oils from six C. osmophloeum provenances (Table 1, COA-COF) as well as their larvicidal activities against Aedes albopictus, Culex quinquefasciatus, and Armigeres subalbatus larvae. In addition, the mosquito larvicidal activity of cinnamaldehyde congeners was also examined in order to elucidate the effects of chemical structure on the mosquito larvicidal property.

\section{Methods}

\subsection{Plant material and essential oil extraction}

Mature leaf of one C. osmophloeum provenance (COA, CO2001) was collected in August, 2003 from Haw-Lin experimental forest located in Taipei. Mature leaf of one C. osmophloeum provenance (COB, CO1102) was collected in October, 2003 from the Da-Pin-Ting of the Taiwan Sugar Farm and mature leaves of four C. osmophloeum provenances (COC-COF, CO0901, CO1701, CO0602, CO0501) were collected from the Lien Hua-Chin Research Center in July 2003, both locations are situated in Nantou County of central Taiwan. The species were identified by Mr. Yen-Ray Hsui of the Taiwan Forestry Research Institute and the voucher specimens (provenances COA to COF) were deposited at the laboratory of wood chemistry, School of Forestry and Resource Conservation, National Taiwan University. The samples ( $200 \mathrm{~g}$ each), in triplicate, were subjected to hydrodistillation in a Clevenger-type apparatus for 6-h (Cheng et al., 2004), followed by determination of oil contents. The leaf essential oils obtained were separated from the aqueous phase and stored in airtight containers at $4{ }^{\circ} \mathrm{C}$ prior to further analysis.

\section{2. $G C-M S$ analysis}

Analyses of volatile constituents were determined using a Polaris Q Ion Trap GC/FID/MS ${ }^{\mathrm{n}}$ system (Thermo,
USA), equipped with a fused silica column ( $30 \mathrm{~mm} \times 0.25 \mathrm{~mm}$ i.d.) and coated with $5 \%$ phenyl-methylpolysiloxane using a DB-5MS $(\mathrm{df}=0.25 \mu \mathrm{m})$ (Agilent J\&W Scientific, USA). The temperature program used for the analysis was as follows: initial temperature at $80^{\circ} \mathrm{C}$, held for $1 \mathrm{~min}$, ramped at $4{ }^{\circ} \mathrm{C} / \mathrm{min}$ to $200^{\circ} \mathrm{C}$ and held for $5 \mathrm{~min}$. Helium was the carrier gas at $1.0 \mathrm{ml} / \mathrm{min}$; the sample $(1.0 \mu 1,1 / 100, \mathrm{v} / \mathrm{v}$, in ethyl acetate) was injected in the split mode (1:10). The mass spectrometer was equipped with a PoLaris Q mass selective detector in electron impact (EI) ionization mode $(70 \mathrm{eV})$. The ion source temperature and the injector temperature were set at $230^{\circ} \mathrm{C}$ and $270{ }^{\circ} \mathrm{C}$, respectively. The sector mass analyzer was set to scan from 50 to $650 \mathrm{amu}$ every $0.5 \mathrm{~s}$. The Kovats retention indices were calculated for all volatile constituents using a homologous series of $n$-alkanes $\mathrm{C}_{9}-\mathrm{C}_{17}$ on DB-5MS column. Quantification was performed using percentage peak area calculations and the identification of individual components was done using the Wiley/NBS Registry of Mass Spectral Database and NIST MS Search 2.0, the literature (Adams, 2001), and several authentic reference compounds. The relative concentration of each compound in essential oil was quantified according to the peak area integrated by the analysis program.

\subsection{Mosquito larvicidal test}

The free-mating colonies of $A$. albopictus, $C$. quinquefasciatus, and A. subalbatus were established in the insectariums of the Department of Parasitology, Chang-Gung University. The mosquito colonies were maintained continuously at $27^{\circ} \mathrm{C}$ and $80 \pm 10 \%$ relative humidity under a photoperiod of $12: 12 \mathrm{~h}$ (light/dark) cycle, with $10 \%$ yeast suspension used as the growth medium. The method of Momin and Nair (2001) and Cheng et al. (2004) was employed to conduct mosquito larvicidal activity tests. Ten fourth-instar mosquito larvae were placed in $24.5 \mathrm{ml}$ of degassed distilled water, followed by the addition of $500 \mu$ l dimethyl sulfoxide (DMSO) solution containing the test essential oil or the known compound in a $30-\mathrm{ml}$ cup, shaken lightly to ensure a homogeneous test solution, and incubated at the ambient temperature. A total of six essential oils and 26 known compounds were tested in this manner. Essential oils were tested at 400, 200, 100, 50, and $25 \mu \mathrm{g} / \mathrm{ml}$ and each compound was tested at 100, 50, 25, and $12.5 \mu \mathrm{g} / \mathrm{ml}$. The control was prepared with $24.5 \mathrm{ml}$ of degassed distilled water and $500 \mu \mathrm{l}$ of DMSO solution to which larvae were added. Each test was replicated four times. For comparison, commercial chlorpyrifos (o,odiethyl-o-3,5,6-trichloro-2-pyridyl phosphorothioate), an organophosphorus pesticide was used as the positive control. The toxicity of chlorpyrifos was determined at 6.25 , $3.125,1.56,0.78$, and $0.39 \mu \mathrm{g} / \mathrm{ml}$.

Mortality was recorded after 24- and 48-h of exposure, during which no food was given to the larvae. Percent mortality was corrected for control mortality using Abbott's formula, and the results were plotted on $\log$ /probability 
paper using the method of Finney (1971). Toxicity and activity were reported as $\mathrm{LC}_{50}$ and $\mathrm{LC}_{90}$, representing the concentration in $\mu \mathrm{g} / \mathrm{ml}$ that caused 50 and $90 \%$ larval mortality, respectively, in $24-\mathrm{h}$ or 48 -h.

\subsection{Cluster analysis}

The cluster analysis was performed with multi-variate statistical package (MVSP) software to identify relatively

Table 1

Chemical compositions of leaf essential oils from six provenances of C. osmophloeum

\begin{tabular}{|c|c|c|c|c|c|c|c|c|c|c|}
\hline \multirow[t]{2}{*}{ No. } & \multirow[t]{2}{*}{ Compounds } & \multirow[t]{2}{*}{ R.t. $^{\mathrm{a}}$} & \multirow[t]{2}{*}{$\mathrm{KI}^{\mathrm{b}}$} & \multicolumn{6}{|c|}{ Peak area $(\%)$} & \multirow[t]{2}{*}{ Identification $^{\mathrm{c}}$} \\
\hline & & & & $\mathrm{COA}$ & $\mathrm{COB}$ & $\mathrm{COC}$ & COD & $\mathrm{COE}$ & $\mathrm{COF}$ & \\
\hline 1 & $\alpha$-Pinene & 3.74 & 942 & $-{ }^{\mathrm{d}}$ & - & - & - & - & 1.32 & MS, KI, ST \\
\hline 2 & Camphene & 3.97 & 958 & - & - & - & - & - & 1.01 & MS, KI, ST \\
\hline 3 & Benzaldehyde & 4.07 & 965 & 1.18 & 1.19 & 0.49 & 1.55 & - & - & MS, KI, ST \\
\hline 4 & Unidentified & 4.40 & 985 & 1.45 & - & - & - & - & - & \\
\hline 5 & $\beta$-Myrcene & 4.51 & 992 & - & - & - & - & - & 1.42 & MS, KI, ST \\
\hline 6 & $(+)$-Limonene & 5.28 & 1034 & - & - & - & - & 0.40 & 7.39 & MS, KI, ST \\
\hline 7 & 1,8-Cineole & 5.35 & 1038 & 9.21 & - & - & - & - & - & MS, KI, ST \\
\hline 8 & Salicylaldehyde & 5.55 & 1048 & - & - & 0.60 & - & - & 0.85 & MS, KI, ST \\
\hline 9 & trans-Linalool oxide & 6.18 & 1077 & 1.11 & - & - & - & - & - & MS, KI, ST \\
\hline 10 & $c i s$-Linalool oxide & 6.53 & 1091 & 0.91 & - & - & - & 0.41 & - & MS, KI, ST \\
\hline 11 & Linalool & 6.75 & 1100 & 5.16 & - & - & - & 95.13 & - & MS, KI, ST \\
\hline 12 & Camphor & 7.99 & 1152 & - & - & 0.40 & 0.65 & - & 56.78 & MS, KI, ST \\
\hline 13 & Benzenepropanal & 8.33 & 1164 & - & 3.30 & - & 1.61 & - & - & MS, KI, ST \\
\hline 14 & Borneol & 8.53 & 1172 & 0.97 & - & - & - & - & 0.75 & MS, KI, ST \\
\hline 15 & 2-Methylbenzofuran & 8.76 & 1180 & - & - & 9.32 & - & - & - & MS \\
\hline 16 & (-)-Terpinen-4-ol & 8.83 & 1182 & 0.74 & 0.46 & - & - & - & 2.01 & MS, KI, ST \\
\hline 17 & $\alpha$-Terpineol & 9.17 & 1194 & 2.78 & - & - & - & 0.43 & 1.89 & MS, KI, ST \\
\hline 18 & 4-Allylanisole & 9.34 & 1199 & - & 1.43 & 0.76 & 0.72 & 0.56 & - & MS \\
\hline 19 & cis-Cinnamaldehyde & 9.92 & 1221 & - & 0.88 & - & 0.55 & - & - & MS \\
\hline 20 & Unidentified & 10.19 & 1231 & 0.84 & - & - & - & 0.31 & - & \\
\hline 21 & Neral & 10.52 & 1243 & 13.09 & - & - & - & - & - & MS, KI, ST \\
\hline 22 & Geraniol & 10.91 & 1256 & 2.02 & - & - & - & - & - & MS, KI, ST \\
\hline 23 & Geranial & 11.37 & 1271 & 24.13 & - & 3.19 & - & - & 0.89 & MS, KI, ST \\
\hline 24 & trans-Cinnamaldehyde & 11.42 & 1273 & - & 91.09 & - & 36.50 & 1.33 & - & MS, KI, ST \\
\hline 25 & Unidentified & 11.63 & 1279 & 1.11 & - & - & - & - & - & \\
\hline 26 & L-Bornyl acetate & 11.91 & 1288 & 4.13 & 0.56 & 1.04 & 0.70 & - & 21.53 & MS, KI, ST \\
\hline 27 & Unidentified & 12.20 & 1297 & 0.95 & - & - & - & - & - & \\
\hline 28 & Geranyl formate & 12.31 & 1300 & 0.98 & - & - & - & - & - & MS \\
\hline 29 & Cinnamyl alcohol & 12.40 & 1304 & - & - & 2.27 & 0.97 & - & - & MS \\
\hline 30 & Unidentified & 13.27 & 1335 & - & 0.31 & - & - & - & - & \\
\hline 31 & Cinnamyl formate & 13.79 & 1353 & - & - & 1.40 & - & - & - & MS \\
\hline 32 & Unidentified & 13.84 & 1354 & 1.67 & - & - & - & - & - & \\
\hline 33 & Eugenol & 13.98 & 1359 & - & 0.28 & - & 0.57 & - & - & MS, KI, ST \\
\hline 34 & Geranyl acetate & 14.74 & 1383 & 4.64 & - & 4.71 & - & - & 1.01 & MS, KI, ST \\
\hline 35 & Unidentified & 16.07 & 1428 & 0.93 & - & - & 0.41 & 0.60 & - & \\
\hline 36 & Coumarin & 16.30 & 1436 & - & - & 2.67 & - & 0.48 & - & MS, KI, ST \\
\hline 37 & Cinnamyl acetate & 16.60 & 1447 & - & - & 59.65 & 54.31 & - & - & MS, KI, ST \\
\hline 38 & $\delta$-Cadinene & 18.99 & 1527 & 1.09 & - & 1.43 & 0.40 & - & - & MS, KI \\
\hline 39 & Spathulenol & 20.57 & 1582 & 12.55 & - & 0.98 & - & - & - & $\mathrm{MS}, \mathrm{KI}$ \\
\hline 40 & Caryophyllene oxide & 20.74 & 1587 & 1.89 & 0.48 & 3.00 & 0.50 & - & 1.27 & MS, KI, ST \\
\hline 41 & Unidentified & 20.98 & 1595 & - & - & 0.53 & - & - & - & \\
\hline 42 & Unidentified & 21.48 & 1613 & - & - & 0.45 & - & - & - & \\
\hline 43 & T-Cadinol & 22.33 & 1645 & 0.72 & - & 2.34 & - & 0.34 & 1.11 & MS, ST \\
\hline \multirow[t]{9}{*}{44} & $\alpha$-Cadinol & 22.70 & 1659 & 1.13 & - & 2.95 & - & - & 0.77 & MS, KI, ST \\
\hline & \multicolumn{3}{|c|}{ Monterpene hydrocarbons (\%) } & 9.21 & 0.00 & 0.00 & 0.00 & 0.40 & 11.14 & \\
\hline & \multicolumn{3}{|c|}{ Oxygenated monoterpenes $(\%)$} & 60.66 & 1.02 & 9.34 & 1.35 & 95.97 & 84.86 & \\
\hline & \multicolumn{3}{|c|}{ Sesquiterpene hydrocarbons (\%) } & 1.09 & 0.00 & 1.43 & 0.4 & 0.00 & 0.00 & \\
\hline & \multicolumn{3}{|c|}{ Oxygenated sesquiterpenes $(\%)$} & 16.29 & 0.48 & 9.27 & 0.50 & 0.34 & 3.15 & \\
\hline & \multicolumn{3}{|c|}{ Other $(\%)$} & 1.18 & 98.17 & 77.16 & 97.19 & 2.97 & 0.85 & \\
\hline & \multicolumn{3}{|c|}{ Identified components $(\%)$} & 88.22 & 99.67 & 96.22 & 99.44 & 99.68 & 100.00 & \\
\hline & \multicolumn{3}{|c|}{ Unidentified components $(\%)$} & 8.78 & 0.31 & 1.81 & 0.00 & 0.31 & 0.00 & \\
\hline & \multicolumn{3}{|c|}{ Oil yield $(\%)$} & 1.03 & 1.11 & 1.59 & 1.64 & 4.69 & 0.82 & \\
\hline
\end{tabular}

${ }^{\mathrm{a}}$ Retention time (min).

${ }^{\mathrm{b}}$ Kovats retention index relative to $n$-alkanes $\left(\mathrm{C}_{9}-\mathrm{C}_{17}\right)$ on DB-5MS column.

c Identification based on comparison of the mass spectrum, Kovats index on a DB-5MS column in reference (Adams, 2001) and co-injection with authentic compounds.

${ }^{\mathrm{d}}$ Not detected. 
homogeneous groups of six provenances $(\mathrm{COA}-\mathrm{COF})$ of C. osmophloeum according to percent composition of their essential oil samples. Euclidean distance was selected as a measure of similarity, and the unweighted pair-group method with arithmetic average (UPGMA) was used for cluster definition (Pereira et al., 2003).

\subsection{Statistical analysis}

The Scheffe multiple comparison procedure of SAS statistical program was used to analyze the difference in mosquito larvicidal activities among six $C$. osmophloeum leaf essential oils and their constituents $(P<0.05)$. All results were obtained from four independent experiments and expressed as mean $\pm \mathrm{SD}$.

\section{Results and discussion}

\subsection{Yields and chemical polymorphism of essential oils from different provenances}

The essential oil contents of six provenances of C. osmophloeum leaves obtained by hydrodistillation ranged from a minimum of $0.82 \%$ dry weight to a maximum of $4.69 \%$ dry weight (Table 1). The highest oil yield was found in COE $(4.69 \%)$, followed by COD $(1.64 \%)$, COC $(1.59 \%)$, COB (1.11\%), COA $(1.03 \%)$, and COF $(0.82 \%)$.

Table 1 shows the constituents of the six essential oils identified their percentage composition as well as their Kovats index (KI) values listed in order of elution from the DB-5MS capillary column. A total of 36 compounds were identified in the leaf essential oils from the six provenances, representing $88.22 \%$ to $100.00 \%$ of the oils obtained. The compounds from the six essential oils could be assigned to five different classes: monoterpene hydrocarbons (0.00-11.14\%), oxygenated monoterpenes (1.02-95.97\%), sesquiterpene hydrocarbons $(0.00-1.43 \%)$, oxygenated sesquiterpenes $(0.34-16.29 \%)$, and others $(0.85-98.17 \%)$. The leaf essential oils of provenance COA show the presence of 19 identified compounds accounting for $88.22 \%$ of the whole oil with geranial $(24.13 \%)$, neral $(13.09 \%)$, and spathulenol $(12.55 \%)$ as its main constituents. Provenance COB leaf essential oil contained nine identified compounds, accounting for $99.67 \%$ of the whole oil and containing $91.09 \%$ transcinnamaldehyde as the major constituent. Provenance COC leaf essential oil contained 17 identified compounds, accounting for $96.22 \%$ of the whole oil with cinnamyl acetate as the major components (59.65\%) followed by 2-methylbenzofuran $(9.32 \%)$. Provenance COD leaf essential oil contained 12 identified compounds, accounting for $99.44 \%$ of the whole oil with cinnamyl acetate $(54.31 \%)$ and transcinnamaldehyde $(36.50 \%)$ as its main constituents. Provenance COE leaf essential oil contained eight identified compounds, accounting for $99.68 \%$ of the whole oil containing $95.13 \%$ linalool as its main constituents. Provenance COF leaf essential oil contained 15 identified compounds, accounting for $100.00 \%$ of the whole oil with camphor
$(56.78 \%)$ and L-bornyl acetate $(21.53 \%)$ as its main constituents.

The differences in the percent composition of C. osmophloeum essential oils among the six provenances were determined using cluster analysis (Fig. 1). Following the results obtained herein and the previous classification by $\mathrm{Hu}$ et al. (1985), Lee et al. (2003), and Cheng et al. (2004, 2006), we classified the leaf essential oils into six main types, cinnamaldehyde type (COB), cinnamaldehyde/cinnamyl acetate type (COD), cinnamyl acetate type (COC), camphor type (COF), and linalool type (COE), while the essential oil from COA was classified as a mixed type owing to the lack of a dominant compound. The present results plus those obtained by Cheng et al. (2004, 2006) shows that all the leaf essential oils extracted are similar.

\subsection{Mosquito larvicidal activity of essential oils}

A total of the six chemotypes of $C$. osmophloeum leaf essential oil were investigated for their mosquito larvicidal activities against fourth-instar $A$. albopictus larvae primarily. Fig. 2 shows that the cinnamaldehyde type (provenance $\mathrm{COB}$ ) and cinnamaldehyde/cinnamyl acetate type (provenance COD) induced $100 \%$ larval mortality of $A$. albopictus after $24 \mathrm{~h}$ with a dosage of $100 \mu \mathrm{g} / \mathrm{ml}$. However, a dosage of $200 \mu \mathrm{g} / \mathrm{ml}$ of mixed type (provenance COA), cinnamyl acetate type (provenance COC), camphor type (provenance $\mathrm{COF}$ ) and a dosage of $400 \mu \mathrm{g} / \mathrm{ml}$ of linalool type (provenance COE) were required to reach $100 \%$ larval mortality (Fig. 2).

The efficacy of larvicidal performance of six chemotypes of C. osmophloeum leaf essential oil against A. albopictus in $24 \mathrm{~h}$ can be recognized from the comparison of their $\mathrm{LC}_{50}$ and $\mathrm{LC}_{90}$ values (Table 2). Since the essential oils of mixed type (provenance COA), cinnamyl acetate type (provenance COC), linalool type (provenance COE), and camphor type (provenance COF) showed an $\mathrm{LC}_{50}>50 \mu \mathrm{g} / \mathrm{ml}$ against fourth-instar A. albopictus larvae in $24 \mathrm{~h}$ (Table 2),

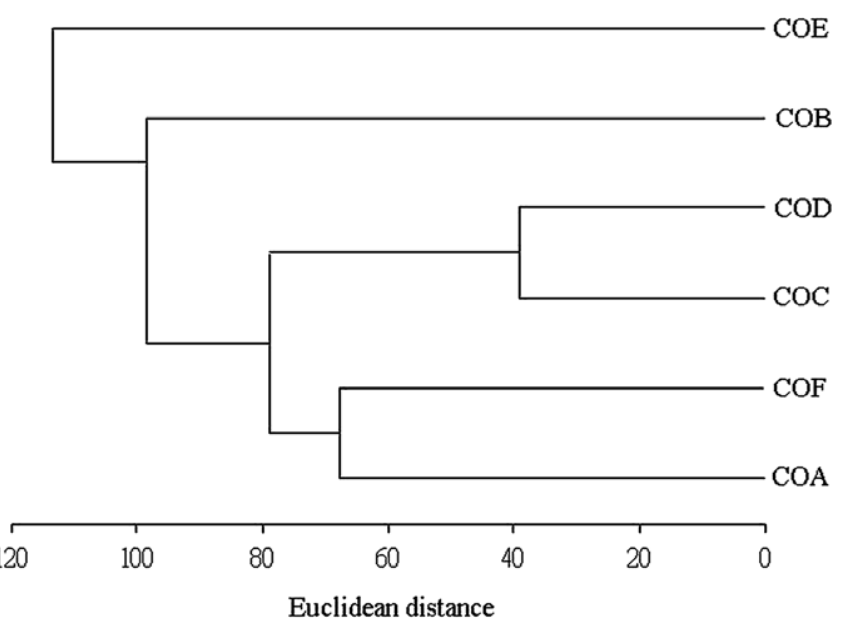

Fig. 1. Dendrogram obtained by cluster analysis of the percentage composition of essential oils from six provenances of C. osmophloeum. 


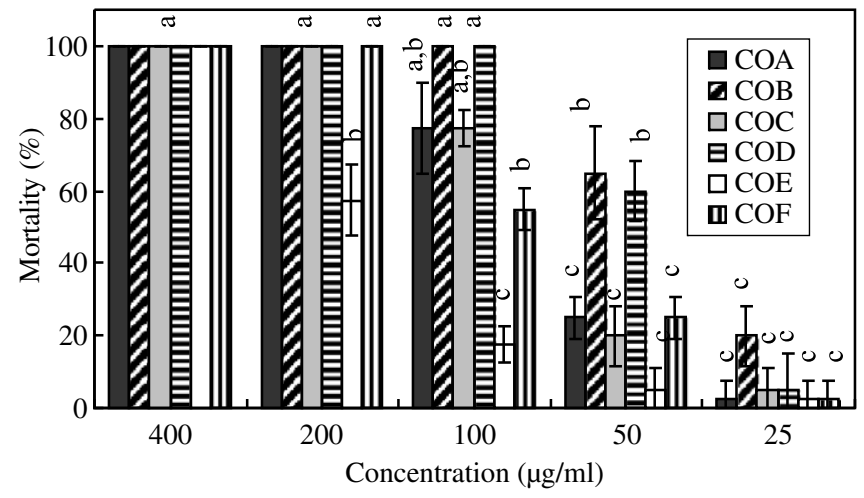

Fig. 2. Mosquito larvicidal activities of leaf essential oils from six chemotypes of $C$. osmophloeum against A. albopictus larvae after $24 \mathrm{~h}$. Means $(n=4)$ using 10 fourth-instar mosquito larvae per replicate. Numbers followed by different letters $(a-c)$ are significantly different at level of $P<0.05$ according to Scheffe's test.

they were consequently considered inactive. Both the cinnamaldehyde type (provenance COB) and cinnamaldehyde/ cinnamyl acetate type (provenance COD) leaf essential oils showed excellent toxicity against $A$. albopictus larvae in $24 \mathrm{~h}$, and the $\mathrm{LC}_{50}$ values were 40.8 and $46.5 \mu \mathrm{g} / \mathrm{ml}$ with corresponding $\mathrm{LC}_{90}$ values of 81.7 and $83.3 \mu \mathrm{g} / \mathrm{ml}$, respectively (Table 2). When incubation was extended to $48 \mathrm{~h}$, the $\mathrm{LC}_{50}$ values of these two chemotypes were $30.5 \mu \mathrm{g} / \mathrm{ml}$ $\left(\mathrm{LC}_{90}=65.6 \mu \mathrm{g} / \mathrm{ml}\right)$ and $45.4 \mu \mathrm{g} / \mathrm{ml}\left(\mathrm{LC}_{90}=81.3 \mu \mathrm{g} / \mathrm{ml}\right)$, respectively. Since cinnamaldehyde type (provenance $\mathrm{COB}$ ) and cinnamaldehyde/cinnamyl acetate type (provenance COD) leaf essential oils contained a higher amount of cinnamaldehyde $(91.09 \%)$ and cinnamyl acetate $(54.31 \%)$, respectively (Table 1 ), which also displayed strong mosquito larvicidal activities, it is clear that the larvicidal activities of these two leaf essential oils are directly affected by the cinnamaldehyde and cinnamyl acetate content. A similar observation was noted in our previous study on the mosquito larvicidal activity of $C$. osmophloeum leaf essential oil against $A$. aegypti larvae ranging between 36 and $44 \mu \mathrm{g} / \mathrm{ml}$ (Cheng et al., 2004). In addition, Cavalcanti

Table 2

$\mathrm{LC}_{50}$ and $\mathrm{LC}_{90}$ values $(\mu \mathrm{g} / \mathrm{ml})$ of leaf essential oils of six chemotypes of $C$. osmophloeum against $A$. albopictus larvae

\begin{tabular}{lrrlrrrl}
\hline Chemotypes $^{\mathrm{a}}$ & \multicolumn{2}{c}{$24 \mathrm{~h}$} & & & $48 \mathrm{~h}$ & & \\
\cline { 2 - 3 } & $\mathrm{LC}_{50}$ & \multicolumn{1}{c}{$\mathrm{LC}_{90}$} & $\mathrm{RP}^{\mathrm{b}}$ & & $\mathrm{LC}_{50}$ & $\mathrm{LC}_{90}$ & $\mathrm{RP}$ \\
\hline $\mathrm{COA}$ & 69.0 & 154.0 & 0.026 & & 64.6 & 147.0 & 0.015 \\
$\mathrm{COB}$ & 40.8 & 81.7 & 0.044 & & 30.5 & 65.6 & 0.033 \\
$\mathrm{COC}$ & 69.8 & 156.9 & 0.026 & & 59.5 & 149.8 & 0.017 \\
$\mathrm{COD}$ & 46.5 & 83.3 & 0.039 & & 45.4 & 81.3 & 0.022 \\
$\mathrm{COE}$ & 144.4 & $>400.0$ & 0.012 & & 124.3 & 368.7 & 0.001 \\
$\mathrm{COF}$ & 77.7 & 183.5 & 0.023 & & 71.7 & 167.1 & 0.014 \\
Chlorpyrifos $^{\mathrm{c}}$ & 1.8 & 2.8 & 1 & & 1.0 & 2.3 & 1 \\
\hline
\end{tabular}

\footnotetext{
${ }^{\text {a }} \mathrm{COA}$, mixed type; $\mathrm{COB}$, cinnamaldehyde type; $\mathrm{COC}$, cinnamyl acetate type; $\mathrm{COD}$, cinnamaldehyde/cinnamyl acetate type; $\mathrm{COE}$, linalool type; COF, camphor type.

${ }^{\mathrm{b}} \mathrm{RP}$, relative potency ( $\mathrm{LC}_{50}$ standard/ $\mathrm{LC}_{50}$ test substance).

${ }^{\mathrm{c}}$ Positive control.
}

et al. (2004) reported that the larvicidal activity of essential oils from Brazilian plants with $\mathrm{LC}_{50}$ values against the larvae of $A$. aegypti ranged from 60 to $69 \mu \mathrm{g} / \mathrm{ml}$. Essential oil from commonly used herbs in Lebanon against Ochlerotatus caspius larvae ranged between 15 and $156 \mu \mathrm{g} / \mathrm{ml}$ (Knio et al., 2008). Pitasawat et al. (2007) also found that the larvicidal activity of five aromatic plant essential oils with $\mathrm{LC}_{50}$ values ranging between 24.6 and $54.6 \mu \mathrm{g} / \mathrm{ml}$ against A. aegypti larvae and ranging from 29.7 to $72.3 \mu \mathrm{g} / \mathrm{ml}$ against Anopheles dirus larvae. Comparisons of the aforesaid results revealed that the leaf essential oils of both cinnamaldehyde type (provenance $\mathrm{COB}$ ) and cinnamaldehyde/cinnamyl acetate type (provenance COD) have excellent mosquito larvicidal activities.

\subsection{Mosquito larvicidal activity of main compounds in essential oils}

To confirm the relationship between the constituents of C. osmophloeum leaf essential oils and mosquito larvicidal activity, 14 main compounds in the leaf essential oils were selected to test their mosquito larvicidal activity against fourth-instar A. albopictus. Chlorpyrifos, well known for its mosquito larvicidal activity, was used in parallel as the positive control. As shown in Table 3, among the 14 compounds tested for $24 \mathrm{~h}$, trans-cinnamaldehyde, cinnamyl acetate, benzaldehyde, eugenol, caryophyllene oxide, citral (mixture of geranial and neral), and T-cadinol exhibited the strongest activity $\left(\mathrm{LC}_{50}<100 \mu \mathrm{g} / \mathrm{ml}\right)$. The $\mathrm{LC}_{50}$ values of these seven compounds were 48.1, 52.7, 47.0, 67.4, 65.6, 70.7 , and $92.7 \mu \mathrm{g} / \mathrm{ml}$, respectively. It is clear that benzaldehyde, trans-cinnamaldehyde, and cinnamyl acetate have the best mosquito larvicidal activity, with $\mathrm{LC}_{50}$ values of $47.0, \quad 48.1$, and $52.7 \mu \mathrm{g} / \mathrm{ml} \quad\left(\mathrm{LC}_{90}=85.5, \quad 89.1\right.$, and $99.3 \mu \mathrm{g} / \mathrm{ml}$ ), respectively. When the test was extended to $48 \mathrm{~h}$, the $\mathrm{LC}_{50}$ and $\mathrm{LC}_{90}$ values of benzaldehyde, trans-cin-

Table 3

$\mathrm{LC}_{50}$ and $\mathrm{LC}_{90}$ values $(\mu \mathrm{g} / \mathrm{ml})$ of 14 compounds in C. osmophloeum leaf essential oils against $A$. albopictus larvae

\begin{tabular}{|c|c|c|c|c|}
\hline \multirow[t]{2}{*}{ Compounds } & \multicolumn{2}{|l|}{$24 \mathrm{~h}$} & \multicolumn{2}{|l|}{$48 \mathrm{~h}$} \\
\hline & $\mathrm{LC}_{50}$ & $\mathrm{LC}_{90}$ & $\mathrm{LC}_{50}$ & $\mathrm{LC}_{90}$ \\
\hline trans-Cinnamaldehyde & 48.1 & 89.1 & 47.4 & 89.1 \\
\hline Cinnamyl acetate & 52.7 & 99.3 & 45.0 & 84.8 \\
\hline Benzaldehyde & 47.0 & 85.5 & 45.4 & 81.3 \\
\hline Camphor & $>100.0$ & $>100.0$ & $>100.0$ & $>100.0$ \\
\hline Benzenepropanal & $>100.0$ & $>100.0$ & $>100.0$ & $>100.0$ \\
\hline 1,8-Cineole & $>100.0$ & $>100.0$ & $>100.0$ & $>100.0$ \\
\hline L-Bornyl acetate & $>100.0$ & $>100.0$ & $>100.0$ & $>100.0$ \\
\hline Eugenol & 67.4 & $>100.0$ & 54.8 & $>100.0$ \\
\hline Caryophyllene oxide & 65.6 & $>100.0$ & 58.3 & $>100.0$ \\
\hline$\alpha$-Terpineol & $>100.0$ & $>100.0$ & $>100.0$ & $>100.0$ \\
\hline Citral & 70.7 & $>100.0$ & 65.4 & $>100.0$ \\
\hline Geranyl acetate & $>100.0$ & $>100.0$ & $>100.0$ & $>100.0$ \\
\hline T-cadinol & 92.7 & $>100.0$ & 74.5 & $>100.0$ \\
\hline Linalool & $>100.0$ & $>100.0$ & $>100.0$ & $>100.0$ \\
\hline Chlorpyrifos $^{\text {a }}$ & 1.8 & 2.8 & 1.0 & 2.3 \\
\hline
\end{tabular}

\footnotetext{
a Positive control.
} 
namaldehyde, and cinnamyl acetate were $45.0-47.4 \mu \mathrm{g} / \mathrm{ml}$ and $81.3-89.1 \mu \mathrm{g} / \mathrm{ml}$, respectively (Table 3 ). Whereas, the $\mathrm{LC}_{50}$ and $\mathrm{LC}_{90}$ values for choropyrifos were $1.8 \mu \mathrm{g} / \mathrm{ml}$ $\left(\mathrm{LC}_{50}=1.0 \mu \mathrm{g} / \mathrm{ml}\right.$ for $\left.48 \mathrm{~h}\right)$ and $2.8 \mu \mathrm{g} / \mathrm{ml}\left(\mathrm{LC}_{90}=2.3 \mu \mathrm{g} /\right.$ $\mathrm{ml}$ for $48 \mathrm{~h}$ ), respectively.

Although benzaldehyde, trans-cinnamaldehyde, and cinnamyl acetate all possess stronger mosquito larvicidal activity, benzaldehyde exists in only small quantity in the leaf essential oils of all C. osmophloeum provenances (COA to COD). In addition, cinnamyl acetate was not found in provenances $\mathrm{COA}-\mathrm{COB}$ and $\mathrm{COE}-\mathrm{COF}$ except in provenances COC $(59.65 \%)$ and COD (54.31\%). Therefore, cinnamaldehyde is clearly responsible for the excellent mosquito larvicidal activity of provenances COB and COD essential oils. Similar results in previous studies on the antibacterial, antitermite, antimite, antimildew, antipathogenic, antimosquito, antifungal, and anti-inflammatory activities of $C$. osmophloeum were obtained by Chang et al. (2001), Chang and Cheng (2002), Chen et al. (2002), Chen and Chang (2002), Cheng et al. (2004, 2006), Lee et al. (2005), Wang et al. (2005), and Chao et al. (2008).

It has been reported that eugenol, thymol, and carvacrol from commonly used herbs in Lebanon were effective against fourth-instar larvae of $O$. caspius with $\mathrm{LC}_{50}$ values of $7.53,33.65$, and $35.48 \mu \mathrm{g} / \mathrm{ml}$, respectively (Knio et al., 2008). Rahuman et al. (2000) also found that $n$-hexadecanoic acid in Feronia limonia dried leaves was effective against fourth-instar larvae of C. quinquefasciatus, Anopheles stephensi, and $A$. aegypti with $\mathrm{LC}_{50}$ values of 129.24 , 79.58 , and $57.23 \mu \mathrm{g} / \mathrm{ml}$, respectively. In another investigation, Kiran et al. (2006) found that pregeijerene, geijerene, and germacrene D isolated from Chloroxylon swietenia DC had $\mathrm{LC}_{50}$ values of $28.3,43.4$, and $63.6 \mu \mathrm{g} / \mathrm{ml}$ when tested against fourth-instar $A$. aegypti larvae and $\mathrm{LC}_{50}$ values of $25.8,41.2$, and $59.5 \mu \mathrm{g} / \mathrm{ml}$ when tested against fourth-instar A. stephensi larvae at $24 \mathrm{~h}$. Comparisons of these data revealed that benzaldehyde, trans-cinnamaldehyde, and cinnamyl acetate examined in this study exhibited great larvicidal performance.

\subsection{Mosquito larvicidal activity of cinnamaldehyde type essential oil and trans-cinnamaldehyde against $C$. quinquefasciatus and A. subalbatus larvae}

The above-mentioned results show that the cinnamaldehyde type leaf essential oil and trans-cinnamaldehyde have significant mosquito larvicidal activities against fourthinstar A. albopictus larvae. Thus, two mosquito larvae of C. quinquefasciatus and A. subalbatus were selected to test the mosquito larvicidal activities of cinnamaldehyde type leaf essential oil and trans-cinnamaldehyde. As shown in Table 4 , the $\mathrm{LC}_{50}$ values of cinnamaldehyde type leaf essential oil against $C$. quinquefasciatus and A. subalbatus larvae in $24 \mathrm{~h}$ were 31.3 and $22.1 \mu \mathrm{g} / \mathrm{ml}$ with corresponding $\mathrm{LC}_{90}$ values of 82.8 and $62.3 \mu \mathrm{g} / \mathrm{ml}$, respectively. When incubation was extended to $48 \mathrm{~h}$, the $\mathrm{LC}_{50}$ values of these two samples were $14.0 \mu \mathrm{g} / \mathrm{ml}\left(\mathrm{LC}_{90}=69.7 \mu \mathrm{g} / \mathrm{ml}\right)$ and 21.8
Table 4

$\mathrm{LC}_{50}$ and $\mathrm{LC}_{90}$ values $(\mu \mathrm{g} / \mathrm{ml})$ of cinnamaldehyde type in C. osmophloeum leaf essential oil and trans-cinnamaldehyde against C. quinquefasciatus and A. subalbtus larvae

\begin{tabular}{|c|c|c|c|c|c|}
\hline \multirow[t]{2}{*}{ Specimens } & \multirow[t]{2}{*}{ Time $(\mathrm{h})$} & \multicolumn{2}{|c|}{ C. quinquefasciatus } & \multicolumn{2}{|c|}{ A. subalbtus } \\
\hline & & $\mathrm{LC}_{50}$ & $\mathrm{LC}_{90}$ & $\mathrm{LC}_{50}$ & $\mathrm{LC}_{9}$ \\
\hline \multirow[t]{2}{*}{ Cinnamaldehyde type oil } & 24 & 31.3 & 82.8 & 22.1 & 62.3 \\
\hline & 48 & 14.0 & 69.7 & 21.8 & 36.5 \\
\hline \multirow[t]{2}{*}{ trans-Cinnamaldehyde } & 24 & 37.5 & 80.6 & 27.6 & 70.2 \\
\hline & 48 & 18.3 & 68.4 & 23.8 & 65.7 \\
\hline
\end{tabular}

$\mu \mathrm{g} / \mathrm{ml} \quad\left(\mathrm{LC}_{90}=36.5 \mu \mathrm{g} / \mathrm{ml}\right)$, respectively. On the other hand, the $\mathrm{LC}_{50}$ values of trans-cinnamaldehyde against $C$. quinquefasciatus and A. subalbatus larvae in $24 \mathrm{~h}$ were 37.5 and $27.6 \mu \mathrm{g} / \mathrm{ml}$ with corresponding $\mathrm{LC}_{90}$ values of 80.6 and $70.2 \mu \mathrm{g} / \mathrm{ml}$, respectively. When incubation was extended to $48 \mathrm{~h}$, the $\mathrm{LC}_{50}$ values of these two samples were $18.3 \mu \mathrm{g} / \mathrm{ml} \quad\left(\mathrm{LC}_{90}=68.4 \mu \mathrm{g} / \mathrm{ml}\right)$ and $23.8 \mu \mathrm{g} / \mathrm{ml} \quad\left(\mathrm{LC}_{90}=\right.$ $65.7 \mu \mathrm{g} / \mathrm{ml}$ ), respectively (Table 4). In addition, it is obvious that $A$. subalbtus larvae proved to be more sensitive to trans-cinnamaldehyde than $C$. quinquefasciatus and $A$. albopictus larvae.

Our results showed that cinnamaldehyde type leaf essential oil was more potent than trans-cinnamaldehyde against A. albopictus, C. quinquefasciatus, and A. subalbatus larvae. The observation may be attributable to the synergistic effect of other components of the cinnamaldehyde type leaf essential oil. The results obtained herein suggest that cinnamaldehyde type leaf essential oil should have a strong potential as larvicide against different mosquitoes.

\subsection{Structure-activity relationship study of trans- cinnamaldehyde's congeners}

According to the results obtained in this study, transcinnamaldehyde is the strongest mosquito larvicidal compound in the leaf essential oils of $C$. osmophloeum. Thus, to examine the structure-activity relationships of trans-cinnamaldehyde, 15 compounds whose chemical structures are similar to cinnamaldehyde were selected for this study. Table 5 presents the results of $\mathrm{LC}_{50}$ and $\mathrm{LC}_{90}$ values of these compounds against fourth-instar A. albopictus larvae, showing that trans-cinnamaldehyde, benzaldehyde, methyl cinnamate, $\alpha$-methyl cinnamaldehyde were the most active against $A$. albopictus larvae amongst the 16 compounds tested in $24 \mathrm{~h}$, with $\mathrm{LC}_{50}$ values lower than $50.0 \mu \mathrm{g} / \mathrm{ml}$. They are ranked as $\alpha$-methyl cinnamaldehyde $\left(\mathrm{LC}_{50}=\right.$ $\left.31.2 \mu \mathrm{g} / \mathrm{ml} ; \quad \mathrm{LC}_{90}=46.4 \mu \mathrm{g} / \mathrm{ml}\right)>$ benzaldehyde $\quad\left(\mathrm{LC}_{50}=\right.$ $\left.47.0 \mu \mathrm{g} / \mathrm{ml} ; \quad \mathrm{LC}_{90}=85.5 \mu \mathrm{g} / \mathrm{ml}\right)>$ trans-cinnamaldehyde $\left(\mathrm{LC}_{50}=48.1 \mu \mathrm{g} / \mathrm{ml} ; \mathrm{LC}_{90}=89.1 \mu \mathrm{g} / \mathrm{ml}\right)>$ methyl cinnamate $\left(\mathrm{LC}_{50}=50.0 \mu \mathrm{g} / \mathrm{ml} ; \mathrm{LC}_{90}=89.6 \mu \mathrm{g} / \mathrm{ml}\right)$. These results indicated that trans-cinnamaldehyde or $\alpha$-methyl cinnamaldehyde, having an aldehyde group, a conjugated double bond and a length of $\mathrm{CH}$ chain outside the ring, possesses much stronger mosquito larvicidal activity. A similar observation was also noted in our previous studies on the 
Table 5

$\mathrm{LC}_{50}$ and $\mathrm{LC}_{90}$ values $(\mu \mathrm{g} / \mathrm{ml})$ of cinnamaldehyde congeners in mosquito larvicidal assay against $A$. albopictus larvae

\begin{tabular}{|c|c|c|c|c|}
\hline \multirow[t]{2}{*}{ Compounds } & \multicolumn{2}{|l|}{$24 \mathrm{~h}$} & \multicolumn{2}{|l|}{$48 \mathrm{~h}$} \\
\hline & $\mathrm{LC}_{50}$ & $\mathrm{LC}_{90}$ & $\mathrm{LC}_{50}$ & $\mathrm{LC}_{90}$ \\
\hline trans-Cinnamaldehyde & 48.1 & 89.1 & 47.4 & 89.1 \\
\hline Benzenepropanal & $>100.0$ & $>100.0$ & $>100.0$ & $>100.0$ \\
\hline Cinnamyl acetate & 52.7 & 99.3 & 45.0 & 84.8 \\
\hline Cinnamic acid & 82.0 & $>100.0$ & 75.6 & $>100.0$ \\
\hline Cinnamyl alcohol & $>100.0$ & $>100.0$ & 79.0 & $>100.0$ \\
\hline Benzaldehyde & 47.0 & 85.5 & 45.4 & 81.3 \\
\hline 4-Hydroxybenzaldehyde & 80.1 & 128.4 & 74.4 & 122.0 \\
\hline Methyl cinnamate & 50.0 & 89.6 & 43.7 & 78.4 \\
\hline$\alpha$-Methyl cinnamaldehyde & 31.2 & 46.4 & 30.1 & 46.2 \\
\hline 2-Methyl-3-phenyl-2-propen-1-ol & $>100.0$ & $>100.0$ & 61.7 & $>100.0$ \\
\hline 2-Hydroxycinnamic acid & $>100.0$ & $>100.0$ & $>100.0$ & $>100.0$ \\
\hline 3-Hydroxycinnamic acid & $>100.0$ & $>100.0$ & $>100.0$ & $>100.0$ \\
\hline 4-Hydroxycinnamic acid & $>100.0$ & $>100.0$ & $>100.0$ & $>100.0$ \\
\hline 2-Methylcinnamic acid & 64.7 & 95.1 & 61.7 & 94.1 \\
\hline 3-Methylcinnamic acid & 64.1 & 98.9 & 58.3 & 96.4 \\
\hline 4-Methylcinnamic acid & 66.2 & 95.2 & 59.7 & 93.3 \\
\hline Chlorpyrifos $^{\mathrm{a}}$ & 1.8 & 2.8 & 1.0 & 2.3 \\
\hline
\end{tabular}

${ }^{\mathrm{a}}$ Positive control.

antibacterial (Chang et al., 2001), antitermitic (Chang and Cheng, 2002), antimosquito (Cheng et al., 2004), and antifungal (Lee et al., 2005; Wang et al., 2005) activities of $C$. osmophloeum. In addition, on the basis of the mosquito larvicidal activities of the seven cinnamic acid derivatives, the hydroxyl group on the cinnamic acid structure has no significant influence $\left(\mathrm{LC}_{50}>100.0 \mu \mathrm{g} / \mathrm{ml}\right)$ on mosquito larvicidal activity, but the presence of the methyl group may have a considerable influence on the inhibitory action against fourth-instar $A$. albopictus larvae (Table 5). The results differ from those reported by Kim et al. (2004), who suggested that the presence of the hydroxyl moiety in the ortho position may have a considerable influence on the Tyrophagus putrescentiae toxicity. We assume that the discrepancy might be due to the different mechanisms involved in the inhibition of mosquito larvae and mites.

\section{Conclusions}

The use of natural products may be considered as an important alternative insecticide for the control of mosquito larvae. Results from this study demonstrated that the cinnamaldehyde type and cinnamaldehyde/cinnamyl acetate type of $C$. osmophloeum leaf essential oils have excellent mosquito larvicidal activity and that trans-cinnamaldehyde is responsible for such activity. Furthermore, trans-cinnamaldehyde as well as the cinnamaldehyde type and cinnamaldehyde/cinnamyl acetate type essential oils are natural and more selective larvicide against $A$. albopictus, C. quinquefasciatus, and A. subalbatus larvae. However, further investigations for the insecticidal action mode of trans-cinnamaldehyde, effects on non-target organisms and field evaluation are needed. Accordingly, these results could be useful in the research for selecting newer, more selective, biodegradable and natural larvicidal compounds.

\section{Acknowledgements}

This study was supported by a grant from the Council of Agriculture (COA) of the Executive Yuan, Taiwan. The authors thank COA for the financial support, Mr. YenRay Hsui of the Taiwan Forestry Research Institute and the Taiwan Da-Pin-Ting Sugar Farm for providing $C$. osmophloeum materials.

\section{References}

Adams, R.P., 2001. Identification of Essential Oil Components by Gas Chromatography/Quadrupole Mass Spectroscopy, Allured, Illinois.

Cavalcanti, E.S.B., Morais, S.M., Lima, M.A.A., Santana, E.W.P., 2004. Larvicidal activity of essential oils from Brazilian plants against Aedes aegypti L.. Mem. Inst. Oswaldo Cruz. 99, 541-544.

Chang, S.T., Chen, P.F., Chang, S.C., 2001. Antibacterial activity of leaf essential oils and their constituents from Cinnamomum osmophloeum. J. Ethnopharmacol. 77, 123-127.

Chang, S.T., Cheng, S.S., 2002. Antitermitic activity of leaf essential oils and components from Cinnamomum osmophloeum. J. Agric. Food Chem. 50, 1389-1392.

Chang, H.T., Cheng, S.S., Chang, S.T., Su, Y.C., Tsai, K.H., Chen, W.J., 2003. Mosquitocidal activity of leaf essential oil and its components from Calocedrus formosana. Quart. J. Chin. For. 36, 73-79.

Chao, L.K., Hua, K.F., Hsu, H.Y., Cheng, S.S., Liu, J.Y., Chang, S.T., 2005. Study on the anti-inflammatory activity of essential oil from leaves of Cinnamomum osmophloeum. J. Agric. Food Chem. 53, 7274 7278.

Chao, L.K., Hua, K.F., Hsu, H.Y., Cheng, S.S., Lin, I.F., Tsai, R.Y., Chen, S.T., Chang, S.T., 2008. Cinnamaldehyde inhibits pro-inflammatory cytokines secretion from monocytes/macrophages through suppression of intracellular signaling. Food Chem. Toxicol. 46, 220231.

Chen, P.F., Chang, S.T., 2002. Application of essential oils from wood on the manufacture of environment-friendly antimicrobial paper products. Quart. J. Chin. For. 35, 69-74.

Chen, P.F., Chang, S.T., Wu, H.H., 2002. Antimite activity of essential oils and their components from Cinnamomum osmophloeum. Quart. J. Chin. For. 35, 397-404.

Cheng, S.S., Chang, H.T., Chang, S.T., Tsai, K.H., Chen, W.J., 2003. Bioactivity of selected plant essential oils against the yellow fever mosquito Aedes aegypti larvae. Bioresour. Technol. 89, 99-102.

Cheng, S.S., Liu, J.Y., Tsai, K.H., Chen, W.J., Chang, S.T., 2004. Chemical composition and mosquito larvicidal activity of essential oils from leaves of different Cinnamomum osmophloeum provenances. J. Agric. Food Chem. 52, 4395-4400.

Cheng, S.S., Liu, J.Y., Hsui, Y.R., Chang, S.T., 2006. Chemical polymorphism and antifungal activity of essential oils from leaves of different provenances of indigenous cinnamon (Cinnamomum osmophloeum). Bioresour. Technol. 97, 306-312.

Cheng, S.S., Huang, C.G., Chen, W.J., Kuo, Y.H., Chang, S.T., 2008. Larvicidal activity of tectoquinone isolated from red heartwood-type Cryptomeria japonica against two mosquito species. Bioresour. Technol. 99, 3617-3622.

Fatope, M.O., Ibrahim, H., Takeda, Y., 1993. Screening of higher plants reputed as pesticides using the brine shrimp lethality assay. Int. J. Pharmacognosy 31, 250-254.

Finney, D.J., 1971. Probit Analysis: A Statistical Treatment of the Sigmoid Response Curve, third ed. Cambridge University Press, Cambridge, pp. 9-158, 318.

Hemingway, J., 2004. Taking aim at mosquitoes. Nature 430, 936. 
Hu, T.W., Lin, Y.T., Ho, C.K., 1985. Natural variation of chemical components of the leaf oil of Cinnamomum osmophloeum Kaneh. Bull. Taiwan For. Res. Inst. Eng. 78, 296-313.

Jantan, I., Yalvema, M.F., Ahmad, N.W., Jamal, J.A., 2005. Insecticidal activities of the leaf oils of eight Cinnamomum species against Aedes aegypti and Aedes albopictus. Pharmaceutical Biol. 43, 526-532.

Jayaprakasha, G.K., Jagan Mohan Rao, L., Sakariah, K.K., 2003. Volatile constituents from Cinnamomum zeylanicum fruit stalks and their antioxidant activities. J. Agric. Food Chem. 51, 4344 4348 .

Kim, H.K., Kim, J.R., Ahn, Y.J., 2004. Acaricidal activity of cinnamaldehyde and its congeners against Tyrophagus putrescentiae (Acari: Acaridae). J. Stored Prod. Res. 40, 55-63.

Kiran, S.R., Bhavani, K., Devi, P.S., Rao, B.R.R., Reddy, K.J., 2006. Composition and larvicidal activity of leaves and stem essential oils of Chloroxylon swietenia DC against Aedes aegypti and Anopheles stephensi. Bioresour. Technol. 97, 2481-2484.

Knio, K.M., Usta, J., Dagher, S., Zournajian, H., Kreydiyyeh, S., 2008. Larvicidal activity of essential oils extracted from commonly used herbs in Lebanon against the seaside mosquito, Ochlerotatus caspius. Bioresour. Technol. 99, 763-768.

Kuo, P.M., Chu, F.H., Chang, S.Y., Hsiao, W.F., Wang, S.Y., 2007. Insecticidal activity of essential oil from Chamaecyparis formosensis. Holzforschung 61, 595-599.

Lee, H.C., Cheng, S.S., Liu, J.Y., Chang, S.T., 2003. Chemical polymorphism of leaf essential oils from different geographical provenances of indigenous cinnamon (Cinnamomum osmophloeum). Quart. J. Chin. For. 36, 411-422.
Lee, H.C., Cheng, S.S., Chang, S.T., 2005. Antifungal property of the essential oils and their constituents from Cinnamon osmophloeum leaf against tree pathogenic fungi. J. Sci. Food Agric. 85, 20472053.

Lee, M.S., Huang, K.P., Chen, T.C., Lu, P.L., Chen, T.P., 2006. Clinical characteristics of dengue and dengue hemorrhagic fever in a medical center of southern Taiwan during the 2002 epidemic. J. Micro. Immun. Infect. 39, 121-129.

Momin, R.A., Nair, M.G., 2001. Mosquitocidal, nematicidal, and antifungal compounds from Apium graveolens L. seeds. J. Agric. Food Chem. 49, 142-145.

Pereira, S.I., Santos, P.A.G., Barroso, J.G., Figueiredo, A.C., Pedro, L.G., Salgueiro, L.R., Deans, S.G., Scheffer, J.J.C., 2003. Chemical polymorphism of the essential oils from populations of Thymus caespititius grown on the islands Pico, Faial and Graciosa (Azores). Phytochem. Anal. 14, 228-231.

Pitasawat, B., Champakaew, D., Choochote, W., Jitpakdi, A., Chaithong, U., Kanjanapothi, D., Rattanachanpichai, E., Tippawangkosol, P., Riyong, D., Tuetun, B., Chaiyasit, D., 2007. Aromatic plant-derived essential oil: An alternative larvicide for mosquito control. Fitoterapia 78, 205-210.

Rahuman, A.A., Gopalarkrishnan, G., Saleem, G., Arumrgam, S., Himalayan, B., 2000. Effect of Feronia limonia on mosquito larvae. Fitoterapia 71, 553-555.

Wang, S.Y., Chen, P.F., Chang, S.T., 2005. Antifungal activities of essential oils and their constituents from indigenous cinnamon (Cinnamomum osmophloeum) leaves against wood decay fungi. Bioresour. Technol. 96, 813-818. 